\title{
Poética, estética y razón pública en la crítica literaria de Andrés Bello
}

\author{
Alvaro Kaempfer \\ Gettysburg College
}

La poesía, en Andrés Bello, está ligada a la irrupción, cohesión e integridad de las jóvenes repúblicas latinoamericanas a partir de una tradición hispana cuya genealogía se hunde en el mundo clásico y habría sido forjada en diálogo con textos propios y ajenos. Esa apelación al imaginario clásico, anota Juan Durán Luzio, fue compartida por diversas figuras del ciclo independentista (65). La presunta universalidad de su legado anima en Bello un comparatismo cultural desde el que explora culturas y sociedades en relación con la marcha del Occidente que se reproduciría en las Américas. En tal sentido, "la revolución de la independencia americana no fue, no debió ser, alzamiento reaccionario de las razas indígenas", espeta Miguel Antonio Caro en torno a Bello, "sino guerra de emancipación de la raza española, modificada esta por condiciones peculiares de la vida colonial y de los climas americanos: raza española modificada, no francesa ni británica" (125). En dicho proceso, lengua, política y estética convergen sobre la trayectoria global de un Occidente que tiene en la poesía, desde sus más remotos orígenes, su constitutiva, original y hasta genética fórmula civilizatoria.

Tras llegar a Santiago, desde Londres, Bello afirma en julio de 1829 en El Mercurio Chileno que "[e]n los pueblos que gozan de una civilización antigua, la razón pública se ha formado por la lenta acción de los siglos", en los que han ido "sufriendo grandes intervalos, en los cuales los extravíos y los errores han ocupado el lugar de la sensatez y de la verdadera cultura", lo que le permite decir que "[I]a moda, la ignorancia, el capricho ensalzan algunos modelos, y estos cimentan la opinión, que en semejantes casos aplaude y adopta a ciegas", para terminar sentenciando que "antes que llegue la época del desengaño icuánto papel se ha impreso en balde! iCuánto tiempo se ha perdido!" (OC IX, 291-2). Los extravíos de ese tiempo perdido, por cierto, respondían a una nociva ecuación de moda, ignorancia y capricho que entorpecía la marcha de una sociedad hacia la época del desengaño y de su madurez. Esta edad del desengaño permitía cuestionar la experimentación estética y superar la furia residual de la revolución de independencia para abrazar un orden sujeto a una presunta y sólida tradición propia. La homología de orden y desengaño en una razón pública formada por la lectura de esa tradición, modela una sociedad cuya consolidación política y cultural pasa por su lengua.

Para Bello, "tenemos la fortuna de hallar tan adelantada la obra de la perfección intelectual, que todo está hecho y preparado para nuestros goces y para nuestros progresos" (OC IX, 293). A su juicio, solo cabía superar "la última conmoción política que terminó con el triunfo de Lircay el 17 de abril de 1830", dice Alamiro de Ávila Martel, y darle "solidez al régimen portaliano, 
de orden y progreso para el país" (37). La "nación cuya lengua hablamos ha sufrido una crisis que ha dispensado en suelos extranjeros sus ingenios más esclarecidos", allí, afirma Bello, "sin las trabas del doble despotismo político y religioso que los aquejaba, han ampliado la esfera de sus trabajos y los han puesto al nivel de los hombres superiores de los pueblos más cultos" (OC IX, 293). Dicha experiencia, afirma Emir Rodríguez Monegal, nos lleva a su vida "en Inglaterra entre los emigrados españoles y los representantes diplomáticos de naciones hispanoamericanas" (118). En esa comunidad de ciudadanos de una lengua había aprendido de los que veía como los hombres superiores de los pueblos más cultos.

Bello, dice Sergio Grasses, "quiso incorporar la civilización en Hispanoamérica -emancipada políticamente- al movimiento universal de las ciencias y las letras, pidiendo prestado a Europa directrices y procedimientos" (8). En tal sentido, añade Luis Bocaz "el nuevo sujeto de la organización cultural aparece definido en sus trabajos bajo la noción instrumental de 'gente educada'" (178). Por eso, tras acusar, en El Araucano de octubre de 1848, "[e]l estado lastimoso de corrupción en que va cayendo entre nosotros la lengua nativa", Bello plantea que la situación "no podrá remediarse sino por la lectura de las buenas obras clásicas castellanas" (OC IX, 739). En artículos de fines de 1841 e inicios de 1842, Bello indica que "[I]a poesía romántica es de alcurnia inglesa, como el gobierno representativo y el juicio por jurados. Sus irrupciones han sido simultáneas con las de la democracia en los pueblos del mediodía de Europa", añadiendo que quienes "han lidiado contra el progreso en materia de legislación y gobierno, han sustentado no pocas veces la lucha contra la nueva revolución literaria defendiendo a todo trance las antiguallas autorizadas por el respeto supersticioso de nuestros mayores" (OC IX, 376). Si bien reponer la agricultura y afianzar la paz eran prioridades tras la independencia, Bello creía que el desafío decisivo era la educación (Barnola, 97; Amunátegui, 342). En ese contexto, liga el futuro al retorno, desde las Américas, a una estética y a una formación clásica.

Bello abraza la continuidad de una tradición propia que no se limita a la poesía, pero surge modelada por una sensibilidad delineada por esa tradición. No se trata de una regresión temporal sino de una poética de restauración fundacional. En julio de 1848, en la Revista de Santiago, Bello le declara la "guerra a las extravagancias de la llamada libertad literaria que, so color de sacudir el yugo de Aristóteles y Horacio, no respeta ni la lengua ni el sentido común, quebranta a veces hasta las reglas de la decencia, insulta a la religión, y piensa haber hallado una nueva especie de sublime en la blasfemia", por lo que agradece la revisión de los límites del romanticismo hecha por Alberto Lisa y Aragón en sus Ensayos literarios y críticos, a partir de la tradición hispana, para "determinar el sentido de esta palabra, averiguando hasta qué punto puede reconocerse el romanticismo como racional y legítimo" (OC IX, 449). Sobresalen aquí, una vez más, los criterios que ordenan su evaluación de una poética: racionalidad y legitimidad. En tal sentido, Bello no rechazaría el romanticismo, sino que exige buscar "en el espíritu de la sociedad moderna (...) el carácter del romanticismo" (OC IX, 459). En rigor, es una cuestión interpretativa y, sobre todo, de disputar la lectura que el romanticismo haría de la tradición castellana. 
El romanticismo respondería al ejercicio de una libertad estética al interior de una tradición hispana donde, lejos de excesos y represiones, aspira a que converjan poética pública y estética. Isaías García Aponte considera que para Bello "la idea de orden no debe ser una simple verdad de la razón; ella debe ser también una verdad del corazón, es decir, una verdad que pueda hacer llamado al aspecto sentimental del ser humano" (227). En mayo de 1833, en El Araucano, aunque lamenta "el mal que no puede menos de producir la lectura de tantos escritos en que se hace descaradamente la guerra a la religión y a los principios conservadores de las sociedades humanas", Bello está convencido que "este mal existe, ha existido siempre, y las medidas de precaución que se han puesto en práctica no han hecho más que agravarlo, produciendo al mismo tiempo otros inconvenientes gravísimos" (OC IX, 721). Su posición no se ordena bajo una defensa de la plena y libre circulación de ideas, sino que a partir del delicado equilibrio entre libertad poética, debate público e inutilidad del carácter contraproducente de la censura.

En febrero de 1841, a propósito de La Araucana de Alonso de Ercilla, Bello hurga en una larga historia cultural que recupera, desplaza o difumina géneros literarios, porque "[a] cada época social, a cada modificación de la cultura, a cada nuevo desarrollo de la inteligencia, corresponde una forma peculiar de historias ficticias", para concluir que la forma dominante "de nuestro tiempo es la novela" (OC IX, 355). Por tanto, la posibilidad de imaginar estéticamente las sociedades americanas desde la poesía, en los años 1820, da paso a la prosa, a la novela, como el género de un nuevo tiempo. Tras el desengaño, la novela sería el género del desengaño para una sociedad que marcha hacia la madurez. No se trata tanto de desplazar la lírica como género sino asumir que la narración sería el procedimiento dominante en el verso como en la prosa.

Para Bello, "lo que caracteriza las historias ficticias que se leen hoy con más gusto, ya estén escritas en prosa o en verso, es la pintura de la naturaleza física y moral reducida a sus límites" (OC IX, 355). Es una constante en Bello, dice Graciela Montaldo (6). No se trata solo de una selección de formas sino de modalidades poéticas de relación con la realidad histórica. En tal sentido, la separación de lo legible y lo escribible, lleva a Bello decir que quien "introdujese hoy día la maquinaria de la Jerusalem Libertada en un poema épico, se expondría ciertamente a descontentar a sus lectores" (OC IX, 355). De hecho, "exceptuando los romances líricos, y algunas escenas de las comedias", reitera Bello en 1841, "son raros desde el siglo XVII en la poesía castellana los pasajes que hablan el idioma nativo del espíritu humano. Hay entusiasmo, hay calor; pero la naturalidad no es el carácter dominante" (OC IX, 362). Estas expectativas delinearían la primacía de algunos géneros literarios, lo que hurga, ahora en la novela, al reflexionar precisamente respecto de la relación entre poética y razón pública a partir de los años 1840.

A pesar de los cambios, el manejo del idioma y la educación estética era un desafío persistente. Sobre todo, como dice en un artículo de La Biblioteca Americana de 1823, acerca de Nicasio Álvarez, porque la fortaleza creativa y estética del castellano estarían siendo socavadas. No se trataría, plantea Bello, de "sacar a plaza los descuidos y errores (si acaso lo son) de un escritor 
respetable, sino porque tales innovaciones, lejos de enriquecer el idioma, confunden las acepciones recibidas, y dañan a la claridad", lo que considera, una y otra vez, la "prenda la más esencial del lenguaje, y, por una fatalidad del castellano, la más descuidada en todas las épocas de su literatura" (OC IX, 204). Su defensa de una poesía de la claridad no ignora la oscuridad propia del lenguaje poético castellano. Tal oscuridad es un desafío para la creatividad del escritor cuya voluntad estética y normativa de la lengua es comparable al desafío que el texto le impone al lector. Sin embargo, el énfasis crítico de Bello sobre Nicasio Álvarez, se detiene "en el estilo sublime, un entusiasmo forzado; en el patético, una como melindrosa y femenil ternura. Este último es, en nuestra opinión, el más grave y ha plagado hasta su prosa" (OC IX, 210). Aquí, liga la demanda por disciplina estética al reclamo normativo de masculinidad en el lenguaje poético, lo que considera relevante para asegurar lingüística y literariamente la reproducción letrada de un país.

Al revisar los Ejercicios populares de lengua castellana de Pedro Fernández Garfias, en mayo de 1842 y esta vez en El Mercurio de Valparaíso, Bello sostiene que "[s]i el estilo es el hombre, según Buffon, ¿cómo podría permitirse al pueblo la formación a su antojo del lenguaje, resultando que cada cual vendría a tener el suyo, y concluiríamos con otra Babel?", lo que le permite sostener que "[e]n las lenguas como en la política, es indispensable que haya un cuerpo de sabios, que así dicte las leyes convenientes a sus necesidades, como las del habla en que ha de expresarlas", concluyendo, de manera taxativa, que "no sería menos ridículo confiar al pueblo la decisión de sus leyes, que autorizarle en la formación del idioma" (OC IX, 439). EI sello normativo tiene allí un carácter autoritario, como en un artículo de su periodo londinense cuando, en El Repertorio Americano en octubre de 1826, evalúa las propuestas poéticas en boga al abordar los estudios sobre Virgilio hecho por P.F. Tissot. Allí, donde Bello afirma que "el gusto, inseparable de la razón, se ha hecho severo; y cada cual, mediante las lecciones de la experiencia, ha aprendido a juzgar por sí mismo", lo que permitiría, también, que "[I]os amigos de las letras, restituidos a la naturaleza, percibieron todo el mérito de la antigüedad, y reconocieron que el verdadero medio de aventajar a los modernos era igualar a los antiguos" (OC IX, 218). Es la persistente alusión a las raíces europeas, como dice Antonio Scocozza (57). Esa voluntad estética de restauración clásica es la vara con que lee diversos poetas hispanoamericanos, como sucede con José María de Heredia en un artículo publicado por El Repertorio Americano en enero de 1827. Allí, Bello conmina a Heredia a preocuparse de "las composiciones destinadas a los afectos domésticos e inocentes, y menos las del género erótico, de que tenemos ya en nuestra lengua una perniciosa superabundancia" (OC IX, 242). No solo cuestiona el lenguaje y la sensibilidad del escritor cubano, sino que, sobre todo, su visión poética.

Bello separa las fallas que le endosa a la juventud del poeta, las que, cree, podrían superarse con la edad, de las que responden al "país en que nació y se educó" (2 OC IX, 42-3). Aquí, la jerarquía y naturalización de una tradición normativa sobre la cartografía cultural americana le permiten a Bello ligar los presuntos errores de Heredia a su lenguaje porque al filósofo que analiza y clasifica fenómenos, lo contrapone "al poeta, cuyo oficio es pintarlos" (OC IX, 244). Además de rechazar la corrupción y ciertos usos 
del idioma poético, Bello alude, en 1827 a "un defecto comunísimo en los americanos", esa vez sobre Juan Cruz Varela, "que es el de unir en una sílaba dos vocales que naturalmente no forman diptongo, licencia permitida de cuando en cuando (aunque no en toda combinación de vocales); pero que, si se usa inmoderadamente, ofende y es un indicio de hábitos de pronunciación viciosa" (OC IX, 249). La corrupción de la escritura por el habla, y su impacto en el lenguaje estético de una razón tan poética como pública, podría remediarse educando, modelando el habla a partir de la escritura (Ossandón, 115). Para curarse del mal uso del castellano, por deficientes modelos estéticos, regresa a lo que es su visión permanente. Bello defiende "el estudio (demasiado desatendido entre nosotros) de los clásicos castellanos y de los grandes modelos de la antigüedad" porque, a su juicio, "Ios unos castigarán su dicción, los otros acrisolarán su gusto y le enseñarán a conservar, aun entre los arrebatos del estro, la templanza de imaginación, que no pierde jamás de vista a la naturaleza y jamás la exagera, ni la violenta" (OC IX, 244). La carga normativa de una poética clásica remite a una visión estética y lingüística largamente madurada.

En su "Compendio de historia de la literatura", manual preparado para satisfacer necesidades pedagógicas del Instituto Nacional en 1850, la visión de la lengua y de la poesía sostiene en Bello el comparatismo cultural mencionado previamente. Como dice Germán Arciniegas, "no se trataba de traducir textos, sino de precisar los fenómenos más complejos que determinan lo que se ha llamado el genio de las lenguas. Naturalmente, los idiomas eran, para los hombres de entonces, "instrumentos de emancipación" (15). A base de diversos estudios (Sismondi, Chasles, etc.), Bello hace de ese Manual un recorrido tan estético como pedagógico que comienza buscando en la India una genialidad que apenas observa en Egipto y no ve en Babilonios, Caldeos y Asirios, de los que subraya su falta de poesía (OC IX, 11). Su franco desdén por la cultura musulmana refuerza la primacía de una matriz cristiano-hispana cuya transmisión cultural, sin embargo, no desconoce el rol. Niega la legibilidad de un heroísmo comparable al cristiano en las letras árabes. Si Bello retrocede a la tradición hebrea es para subrayar aspectos presuntamente universales del legado de su poesía a la tradición que asume como propia: su entusiasmo divino, su sencillez y austera sublimidad (OC IX, 21). Esta dimensión se pierde con la diáspora, pero regresaría en gloria y majestad con una tradición cristiana tras la matriz poética cultural y civilizatoria que sancionaron los griegos (OC IX, 32-3). Esa herencia es la que nutre su propia formación y la que llegaría a las Américas (Pagni, 47). En esa mirada global, Bello subraya en China una literatura donde el brillo y la elocuencia poética se pierden bajo la "extremada menudencia de los pormenores, la sequedad, el prosaísmo, la pintura fina, delicada, pero fría y monótona, de los más ligeros incidentes" (41). En esas mediaciones, no siempre claras en un texto tan didáctico como normativo, surge con relativa nitidez la perspectiva histórica de su concepción estética y cultural.

Bajo esta visión global, Bello ordena no solo una trayectoria cultural de las letras en diversas culturas, historias y momentos, sino que, sobre todo, la plataforma que ordena su proyecto político, poético e, incluso, constitucional. La convergencia de poética y política responde a una lectura de una estética clásica preservada y apropiada por la tradición hispana. Su postulación como 
modelo cultural cruza los más diversos ámbitos y actividades necesarias para enfrentar la consolidación de un orden tras las fracturas generadas por las guerras independentistas. Es allí donde la literatura y la crítica literarias encuentran no solo su lugar natural, sino que imperativo en la práctica intelectual de Andrés Bello.

\section{Obras citadas}

Amunátegui, Miguel Luis. Vida de Don Andrés Bello. Santiago de Chile: Pedro Ramírez Impresor, 1882.

Arciniegas, Germán. El pensamiento vivo de Andrés Bello. Buenos Aires: Losada, 1946.

Barnola, Pedro. La poesía de Bello en sus borradores. Caracas: Imprenta López, 1962.

Bocaz, Luis. Andrés Bello, una biografía cultural. Bogotá: Convenio Bello, 2000.

Caro, Miguel Antonio. Escritos sobre Don Andrés Bello. Ed. Carlos Valderrama Andrade. Bogotá: Instituto Caro y Cuervo, 1981.

De Ávila Martel, Alamiro. Mora y Bello en Chile (1829-1831). Santiago de Chile: Ediciones de la Universidad de Chile, 1982.

Durán Luzio, Juan. Siete ensayos sobre Andrés Bello, el escritor. Santiago de Chile: Editorial Andrés Bello, 1999.

García Aponte, Isaías. Andrés Bello. Contribución al estudio de la historia de las ideas en América. Ciudad de Panamá: Universidad de Panamá, 1964.

Grasses, Pedro. Andrés Bello. El primer humanista de América. Buenos Aires: Ediciones del Tridente, 1946.

Montaldo, Graciela. "El cuerpo de la patria". Hispamérica 23.68 (1994): 3-20.

Ossandón, Carlos. "Andrés Bello y la res publica litterarum". Revista Universum 26.1 (2011): 109-122.

Pagni, Andrea. "Orientalismos americanos?", Trans 12 (2008): 43-50.

Rodríguez Monegal, Emir. El otro Andrés Bello. Caracas: Monte Ávila Editores, 1969.

Scocozza, Antonio. "Cultura e historia en el Chile de Andrés Bello". Revista de Filosofía 30 (1998): 53-72. 